\title{
Synthesis of All-Carbon Disubstituted Bicyclo[1.1.1]pentanes by Iron-Catalyzed Kumada Cross-Coupling**
}

\author{
Jeremy Nugent ${ }^{+}$, Bethany R. Shire ${ }^{+}$, Dimitri F. J. Caputo, Helena D. Pickford, Frank Nightingale, \\ Ian T. T. Houlsby, James J. Mousseau, and Edward A. Anderson*
}

\begin{abstract}
Disubstituted bicyclo[1.1.1]pentanes (BCPs) are important motifs in drug design as surrogates for p-substituted arenes and alkynes. Access to all-carbon disubstituted BCPS via cross-coupling has to date been limited to use of the BCP as the organometallic component, which restricts scope due to the harsh conditions typically required for the synthesis of metallated BCPs. Here we report a general method to access 1,3-C-disubstituted BCPs from 1-iodo-bicyclo[1.1.1]pentanes (iodo-BCPs) by direct iron-catalyzed cross-coupling with aryl and heteroaryl Grignard reagents. This chemistry represents the first general use of iodo-BCPs as electrophiles in crosscoupling, and the first Kumada coupling of tertiary iodides. Benefiting from short reaction times, mild conditions, and broad scope of the coupling partners, it enables the synthesis of a wide range of 1,3-C-disubstituted BCPs including various drug analogues.
\end{abstract}

1,3-Disubstituted bicyclo[1.1.1]pentanes (BCPs) are of high interest in drug discovery as bioisosteres for 1,4disubstituted arenes and alkynes (Figure 1a). ${ }^{[1]}$ Incorporation of these $\mathrm{sp}^{3}$-rich motifs into drug leads often results in pharmacological benefits such as improved solubility, membrane permeability and metabolic stability. ${ }^{[2]}$ However, access to promising $\mathrm{BCP}$-bearing compounds ${ }^{[2 \mathrm{~b}, 3]}$ can be impeded by lengthy and unscalable reaction sequences, in particular where two carbon substituents are required. These challenges have inspired the development of a number of methods to

[*] Dr. J. Nugent, ${ }^{[+]}$B. R. Shire, ${ }^{[+]}$D. F. J. Caputo, H. D. Pickford, F. Nightingale, Prof. E. A. Anderson

Chemistry Research Laboratory, University of Oxford

12 Mansfield Road, Oxford OX1 3TA (UK)

E-mail: edward.anderson@chem.ox.ac.uk

Dr. I. T. T. Houlsby

Syngenta Ltd., Jealott's Hill International Research Centre Bracknell RG42 6EY (UK)

Dr. J. J. Mousseau

Pfizer Medicine Design

Eastern Point Road, Groton, CT 06340 (USA)

$\left[{ }^{+}\right]$These authors contributed equally to this work.

[**: A previous version of this manuscript has been deposited on a preprint server (https://doi.org/10.26434/chemrxiv.12009390.v1).

(1) Supporting information and the ORCID identification number(s) for

(D) the author(s) of this article can be found under: https://doi.org/10.1002/anie.202004090.

of (C) 2020 The Authors. Published by Wiley-VCH Verlag GmbH \& Co. $\mathrm{KGaA}$. This is an open access article under the terms of the Creative Commons Attribution License, which permits use, distribution and reproduction in any medium, provided the original work is properly cited. synthesize 1,3-C-disubstituted BCPs in which installation of the carbon substituents relies on addition of an organometallic nucleophile to the strained $\mathrm{C} 1-\mathrm{C} 3 \sigma$-bond of [1.1.1]propellane ${ }^{[1 \mathrm{e}, 4]}$ followed by palladium-catalyzed cross-coupling of the resulting metallated BCP (Figure $1 \mathrm{~b}$ ). ${ }^{[1 \mathrm{e}, 4 \mathrm{a}, 5]}$ While such methods can generate useful products, the harsh conditions required to achieve the initial nucleophilic addition limit the suitability of this chemistry for industrial applications.

1-Iodobicyclo[1.1.1]pentanes (iodo-BCPs, 1) are attractive substrates for the introduction of carbon substituents on the BCP skeleton. We recently described efficient and functional group-tolerant conditions to access these compounds by atom transfer radical addition of $\mathrm{C}-\mathrm{I}$ bonds to [1.1.1]propellane, under photoredox catalysis $^{[6]}$ or using triethylborane as initiator. ${ }^{[7]}$ As direct palladium-catalyzed cross-coupling of iodo-BCPs can suffer from competing ring fragmentation, ${ }^{[8]}$ approaches to all-carbon disubstituted BCPs from iodo-BCPs have to date necessitated lithiation of the iodide, followed by cross-coupling as the nucleophilic com-

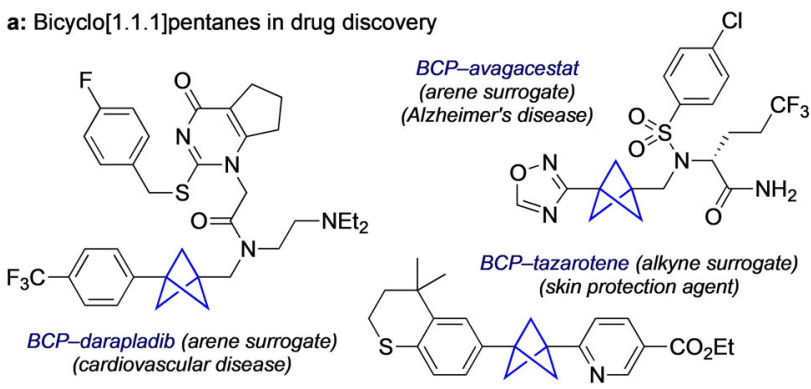

b: Known cross-coupling of metallated BCPs to access 1,3-C-disubstituted BCPs

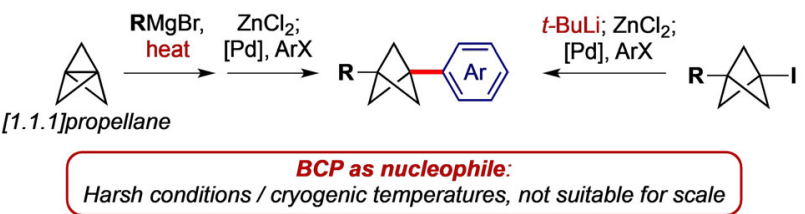

c: This work: Direct iron-catalyzed Kumada cross-coupling of BCP iodides

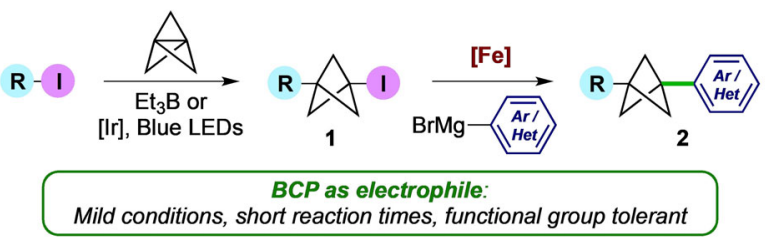

Figure 1. a) Examples of bicyclo[1.1.1]pentanes (BCPs) in medicinal chemistry; b) known cross-coupling of metallated BCPs; c) this work: Direct iron-catalyzed cross-coupling of iodo-BCPs with aryl/ heteroaryl Grignard reagents. 
ponent (Figure $1 \mathrm{~b}$, or reaction with other carbon-based electrophiles)..$^{[1 \mathrm{e}, 4 \mathrm{a}]}$ However, the conditions needed for lithiation of the iodo-BCP again limit scope and scalability.

We targeted an alternative, catalytic method to access allcarbon disubstituted BCPs (2, Figure 1c) directly from iodoBCPs 1, under mild conditions and without recourse to organolithium reagents. Iron-catalyzed Kumada cross-couplings of aryl Grignard reagents with secondary alkyl iodides are an efficient means to achieve $\mathrm{sp}^{3}-\mathrm{sp}^{2} \mathrm{C}-\mathrm{C}$ bond formation, ${ }^{[9]}$ and we questioned whether the tertiary iodide resident in an iodo-BCP could engage in this coupling manifold. While isolated examples of Fe-catalyzed Kumada couplings of tertiary alkyl bromides and chlorides have been described,${ }^{[9 d, 10]}$ the equivalent reaction of tertiary iodides is, to our knowledge, unknown. Here we describe the development of iron-catalyzed cross-coupling reactions of iodo-BCPs with both aryl and heteroaryl Grignard reagents, which represents the first general procedure for the direct cross-coupling of iodo-BCP electrophiles. ${ }^{[11]}$ The chemistry proceeds under mild conditions and short reaction times, displays wide functional group tolerance, and is applicable to the synthesis of drug-like molecules.

Our studies began with the coupling of iodo-BCP $\mathbf{1 a}$ with $p$-methoxyphenylmagnesium bromide (1.6 equiv, $0.7 \mathrm{mLh}^{-1}$ ), which afforded small amounts of coupled product $2 \mathbf{a}$ using $\mathrm{Fe}(\mathrm{acac})_{3}$ or $\mathrm{FeCl}_{3}(20 \mathrm{~mol} \%)$ as catalyst (Table 1, Entries 1, $2)$; the main byproduct was the dehalogenated BCP 3 . Notably, no reaction was seen using $\mathrm{Cu}(\mathrm{acac})_{2}$ (Entry 3). A number of amine and phosphorus ligands were investigated (Entries 4-9) ${ }^{[12]}$ among which ${ }^{\text {TMEDA }}{ }^{[9 \mathrm{a}, \mathrm{b}, 13]}(40 \mathrm{~mol} \%)$ provided the highest yields of $\mathbf{2 a}$ using either a standard Grignard reagent (PMPBr/Mg, 86\%, Entry 8), or the turboGrignard (PMPBr/Mg/LiCl, 79\%, Entry 9). THF was found to be a superior solvent compared to others such as MTBE, 2MeTHF, and toluene (Entries 10-12). ${ }^{[9 \mathrm{~g}, 14]}$ In spite of the failure of $\mathrm{Cu}(\mathrm{acac})_{2}$ alone to catalyze the reaction, we were mindful of the potential presence of trace metals in the $(97 \%$ purity) $\mathrm{Fe}(\mathrm{acac})_{3} \cdot{ }^{[15]}$ However, equivalent reaction efficiency was observed using $\geq 99.9 \% \mathrm{Fe}(\mathrm{acac})_{3}$ (Entry 13 ), and no reaction with $\mathrm{Cu}(\mathrm{acac})_{2} / \mathrm{TMEDA}$ (Entry 14), suggesting this to indeed be an iron-catalyzed transformation. Reducing the loading of catalyst to $10 \mathrm{~mol} \%$ led to lower yields (Entry 15).

With optimized conditions in hand (Table 1, Entries 8/9), the scope of the aryl Grignard coupling partner was examined (Figure 2) using $p$-trifluoromethylbenzyl (1a) and 4- $N$-Bocpiperidyl (1b) iodo-BCPs as representative substrates. Both electron-rich and moderately electron-poor Grignard reagents gave good to excellent yields of the coupled products for para-substituted aryl organometallics (2b-2 m, 53-83\%), with the reaction of 4-trimethylsilylphenylmagnesium bromide also delivering an excellent yield of $\mathbf{2} \mathbf{m}$ on $2.7 \mathrm{mmol}$ scale $(90 \%)$. Substitution at the meta and ortho positions was well tolerated (2n-2r, 55-86\%), although in the latter cases elevated temperatures $\left(45^{\circ} \mathrm{C}\right)$ were required. Bicyclic and trisubstituted Grignard reagents gave similarly high yields of BCP products $\mathbf{2} \mathbf{s}-\mathbf{2} \mathbf{u}(70-72 \%){ }^{[16]}$

The direct coupling of heteroaromatic Grignard reagents would be of high interest in a pharmaceutical context. To our delight, a variety of heteroaryl Grignards underwent success-
Table 1: Reaction optimization. ${ }^{[\mathrm{a}]}$

\begin{tabular}{|c|c|c|c|c|}
\hline $\mathrm{F}_{3} \mathrm{C}$ & 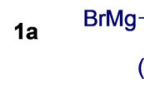 & equiv.) & $2 a$ & $\mathrm{~F}_{3} \mathrm{C}^{\prime}$ \\
\hline Entry & $\begin{array}{l}\text { Catalyst } \\
(20 \text { mol \%) }\end{array}$ & $\begin{array}{l}\text { Additive } \\
\text { (40 } \mathrm{mol} \%)\end{array}$ & Solvent & Yield $^{[\mathrm{b}]}(2 \mathrm{a}: 1 \mathrm{a}: 3)$ \\
\hline 1 & $\mathrm{Fe}(\mathrm{acac})_{3}$ & - & THF & $13: 30: 9$ \\
\hline 2 & $\mathrm{FeCl}_{3}$ & - & THF & $4: 23: 9$ \\
\hline 3 & $\mathrm{Cu}(\mathrm{acac})_{2}$ & - & THF & $0: 100: 0$ \\
\hline 4 & $\mathrm{Fe}(\mathrm{acac})_{3}$ & DMEDA & THF & $5: 22: 9$ \\
\hline 5 & $\mathrm{Fe}(\mathrm{acac})_{3}$ & TMCD & THF & $9: 76: 1$ \\
\hline 6 & $\mathrm{Fe}(\mathrm{acac})_{3}$ & 1,2-DPE & THF & $46: 33: 8$ \\
\hline 7 & $\mathrm{Fe}(\mathrm{acac})_{3}$ & dcypt & THF & $55: 20: 11$ \\
\hline 8 & $\mathrm{Fe}(\mathrm{acac})_{3}$ & TMEDA & THF & $\begin{array}{l}90: 0: 2(86) \\
(86 \%)\end{array}$ \\
\hline $9^{[c]}$ & $\mathrm{Fe}(\mathrm{acac})_{3}$ & TMEDA & THF & $\begin{array}{l}86: 0: 4(79) \\
(86 \%)\end{array}$ \\
\hline 10 & $\mathrm{Fe}(\mathrm{acac})_{3}$ & TMEDA & 2-MeTHF & $71: 15: 2$ \\
\hline 11 & $\mathrm{Fe}(\mathrm{acac})_{3}$ & TMEDA & MTBE & $70: 16: 2$ \\
\hline 12 & $\mathrm{Fe}(\mathrm{acac})_{3}$ & TMEDA & toluene & $79: 0: 3$ \\
\hline $13^{[d]}$ & $\mathrm{Fe}(\mathrm{acac})_{3}$ & TMEDA & THF & $92: 0: 2$ \\
\hline 14 & $\mathrm{Cu}(\mathrm{acac})_{2}$ & TMEDA & THF & $0: 100: 0$ \\
\hline $15^{[\mathrm{e}]}$ & $\mathrm{Fe}(\mathrm{acac})_{3}$ & TMEDA & THF & $75: 7: 3$ \\
\hline
\end{tabular}

[a] 1 a $(0.2 \mathrm{mmol})$, catalyst $(20 \mathrm{~mol} \%)$, additive $(40 \mathrm{~mol} \%)$, solvent $(0.2 \mathrm{~mL}), 20^{\circ} \mathrm{C}$; then add PMPMgBr $(0.8 \mathrm{M}$ in THF, $0.32 \mathrm{mmol})$ added at $0.7 \mathrm{mLh}^{-1}$; then stir, $20^{\circ} \mathrm{C}, 1 \mathrm{~h}$. [b] Yields determined by ${ }^{1} \mathrm{H}$ NMR spectroscopic analysis using 1,3,5-trimethoxybenzene as an internal standard. Isolated yield in parentheses. [c] Using PMPMgBr. $\mathrm{LiCl}(1 \mathrm{M}$ in THF). [d] Using $\geq 99.9 \% \mathrm{Fe}(\mathrm{acac})_{3}$. [e] Using $10 \mathrm{~mol} \% \mathrm{Fe}(\mathrm{acac})_{3}$, $20 \mathrm{~mol} \%$ TMEDA. acac $=$ acetoacetonate. DMEDA $=N, N^{\prime}$-dimethylethylenediamine. dcypt $=3,4$-bis (dicyclohexylphosphino)thiophene. 1,2$\mathrm{DPE}=1,2$-dipiperidinoethane. $\mathrm{MTBE}=$ methyl tert-butyl ether. $\mathrm{PMP}=4$ methoxyphenyl. TMCD $=N, N, N^{\prime}, N^{\prime}$-trans-tetramethylcyclohexanediamine. TMEDA $=N, N, N^{\prime}, N^{\prime}$-tetramethylethylenediamine.

ful reaction to give heteroaryl-functionalized BCPs $\mathbf{2} \mathbf{v}-\mathbf{2} \mathbf{a d}$, albeit warming was required for electron-deficient heterocycles $\left(45^{\circ} \mathrm{C}\right)$. The unsubstituted 3-pyridyl Grignard reagent gave $2 \mathbf{v}$ in a modest $27 \%$ yield, however significant improvement was observed with more electron-rich pyridines $(\mathbf{2} \mathbf{w}-\mathbf{2} \mathbf{y}$, $35-55 \%$ ), although reactions of 2-pyridyl Grignard reagents were unsuccessful. Cross-couplings of benzofuran, $\mathrm{N}$-Bocindoline, $N$-Boc-indole, $N$-methyl indazole, and $N$-phenyl carbazole organometallics were successful, giving good yields of the heteroarylated products $\mathbf{2 z - 2}$ ad (46-67\%).

The scope of the iodo-BCP coupling partner was next investigated in couplings with $\mathrm{PMPMgBr}$. An $N$-Boc azetidine-substituted BCP gave product 2 ae in excellent yield $(73 \%)$. Electron-withdrawing groups were well-tolerated, such as sulfone $\mathbf{2}$ af, and the electrophilic ester $\mathbf{2}$ ag (67\% and $95 \%$ respectively); in the latter case, no addition of the Grignard to the ester was observed. However, a more electrophilic $\alpha, \alpha$-difluoro ester proved less successful (2 ah), likely due to competing addition to the carbonyl. Heteroarylsubstituted iodo-BCPs also proved good substrates, affording the bis-arylated BCP 2 ai in $69 \%$ yield, and double crosscoupled product $\mathbf{2}$ aj in $64 \%$ yield. The chemistry was applied to more complex iodides, with quinoline $\mathbf{2}$ ak and nicotinic 

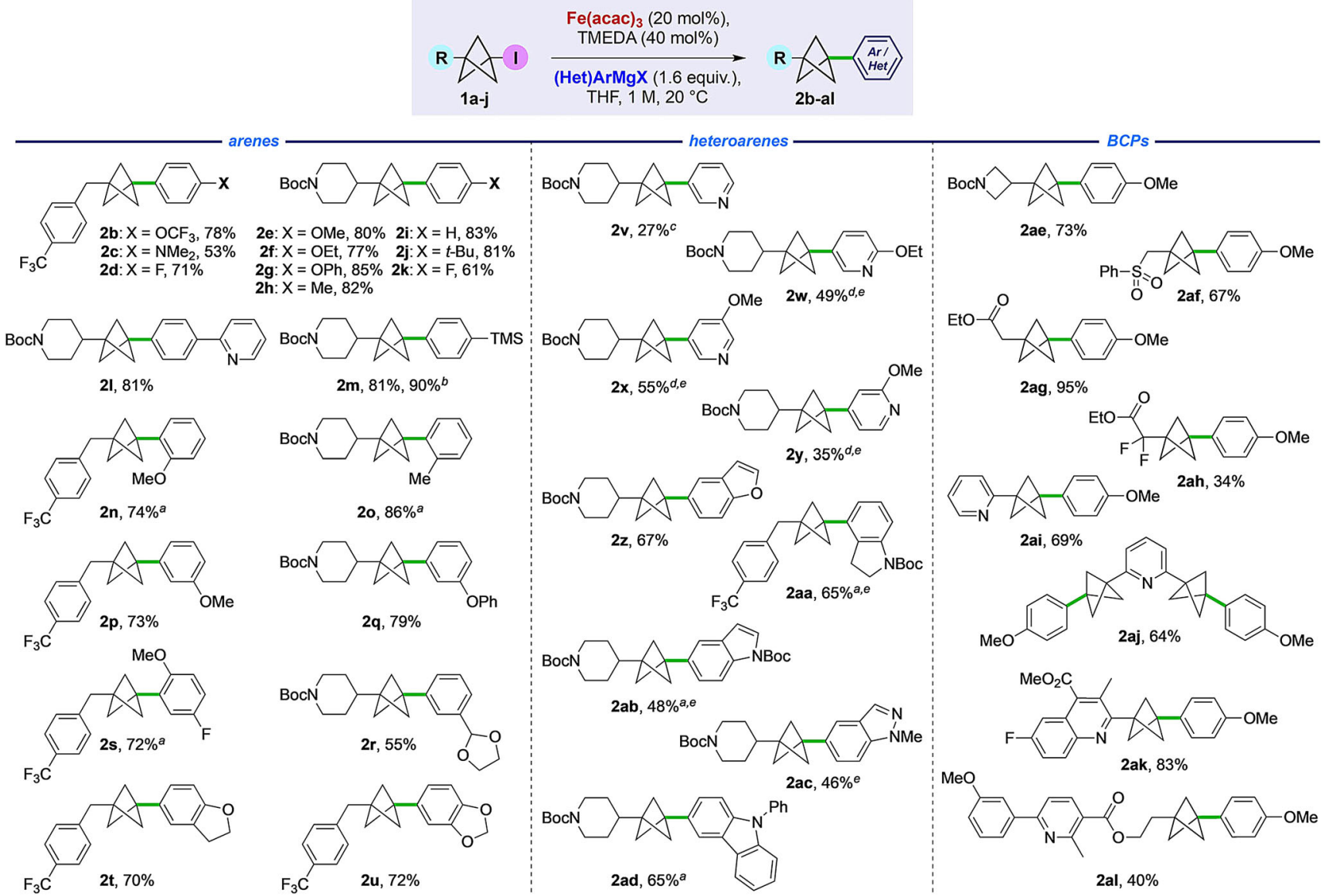

Figure 2. Cross-coupling of electron rich, electron neutral, aryl and heteroaryl Grignard reagents with iodo-BCPs. a) Reaction performed at $45^{\circ} \mathrm{C}$. b) $1.0 \mathrm{~g}$ scale. c) Reaction performed at $65^{\circ} \mathrm{C}$ with rapid addition of the Grignard reagent. d) Reaction performed at $45^{\circ} \mathrm{C}$ with 3 equiv of $\mathrm{Grignard}$ reagent. e) Using (Het)ArMgBr.LiCl.

acid derivative 2 al being formed in $83 \%$ and $40 \%$ yields, respectively. These examples emphasize the mild conditions and functional group tolerance of this methodology.

The mechanistic pathways of iron-catalyzed cross-coupling reactions are dependent on a number of factors, including the nature of the Grignard reagent, the rate of its addition, the additive (ligand), and solvent. ${ }^{[9,17]}$ The formation of iron nanoparticles may also be observed, in particular under a "rapid addition" (of Grignard) regime. ${ }^{[18]}$ In our system, a distinctive colour change from orange/red to dark/ black was observed during Grignard addition which may indicate nanoparticle formation, ${ }^{[19]}$ albeit this is not commonly observed under "slow" addition regimes. ${ }^{[13 a]}$ The presence of substoichiometric TMEDA is also clearly beneficial to reaction efficiency, ${ }^{[9 j, 20]}$ although its role is unclear given evidence that it may not be ligated to the metal during the coupling process. ${ }^{[21]}$

In keeping with couplings carried out using less stericallyhindered aryl Grignard reagents with amine additives, we therefore favour a reaction pathway involving single electron transfer from an $\mathrm{Fe}^{\mathrm{I}}$ species such as $\mathbf{4}^{[17 \mathrm{c}, 22]}$ to the iodo-BCP (Scheme 1), generating a bicyclopentyl radical 5. ${ }^{[23]}$ Reaction of this species with the LArFe(II) complex/ArMgBr liberates the cross-coupled product and results in catalyst turnover;

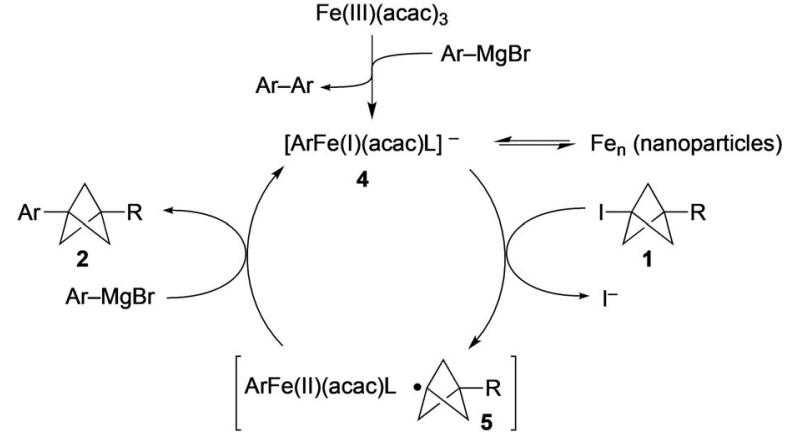

Scheme 1. Putative reaction mechanism.

however, the precise mechanism by which $\mathrm{C}-\mathrm{C}$ bond formation occurs (e.g. in cage/out of cage) is not apparent. ${ }^{[17 a, 24]}$

When combined with our previous methods for iodo-BCP synthesis, the Kumada cross-coupling offers a powerful method for the mild and rapid generation of valuable, pharmaceutically-relevant 1,3-C-difunctionalized BCPs. To demonstrate potential utility, we targeted BCP analogues of the anti-inflammatory drug flurbiprofen, and the anti-neoplastic agent brequinar (Scheme $2 \mathrm{a}$ ). The requisite iodo- 
a
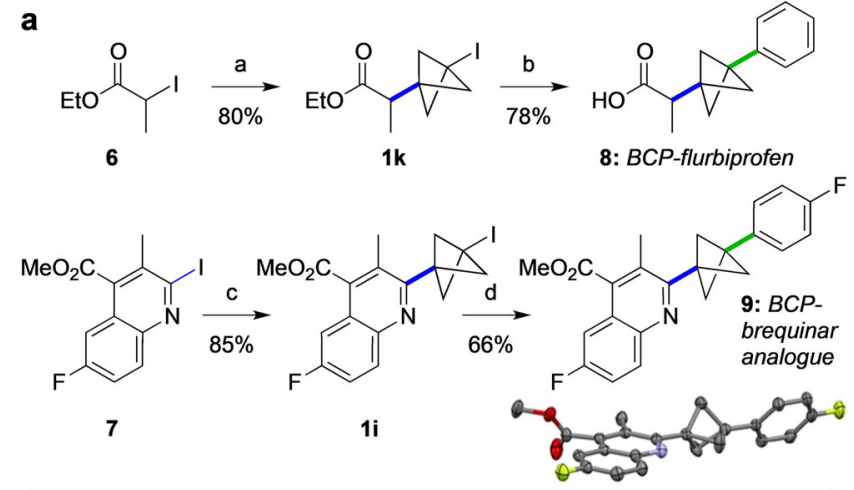

b

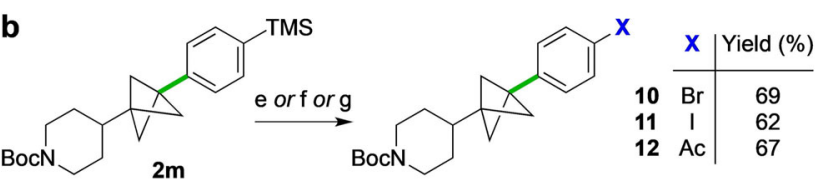

Scheme 2. a) Synthesis of BCP drug analogues. b) Further functionalization. Reagents and Conditions: a) [1.1.1]propellane, $\mathrm{Et}_{3} \mathrm{~B}(10 \mathrm{~mol} \%)$, $\mathrm{Et}_{2} \mathrm{O}, 0^{\circ} \mathrm{C}, 15 \mathrm{~min}$; b) $\mathrm{Fe}(\mathrm{acac})_{3}(20 \mathrm{~mol} \%)$, TMEDA (40 mol\%), $\mathrm{PhMgBr}, \mathrm{THF}, \mathrm{rt}, 1 \mathrm{~h}$, then $\mathrm{NaOH} / \mathrm{MeOH}$; c) Ir $\operatorname{lppy})_{3}(2.5 \mathrm{~mol} \%)$, [1.1.1]propellane, $t$-BuCN, blue LEDs, $24 \mathrm{~h}, 30^{\circ} \mathrm{C}$; d) $\mathrm{Fe}(\mathrm{acac})_{3}$ (20 mol\%), TMEDA (40 mol\%), 4-FPhMgBr, THF, rt, $1 \mathrm{~h}$; e) $\mathrm{KBr}, \mathrm{NCS}$, $\mathrm{AcOH} / \mathrm{MeOH}$, rt; f) ICl, $\mathrm{CH}_{2} \mathrm{Cl}_{2}, 0^{\circ} \mathrm{C}$; g) $\mathrm{AcCl}, \mathrm{AlCl}_{3}, \mathrm{CH}_{2} \mathrm{Cl}_{2}, 0^{\circ} \mathrm{C} \rightarrow \mathrm{rt}$; then $\mathrm{Boc}_{2} \mathrm{O}, \mathrm{Et}_{3} \mathrm{~N}, \mathrm{CH}_{2} \mathrm{Cl}_{2}$, rt. ppy $=$ 2-phenylpyridine.

BCPs $\mathbf{1 k}$ and $\mathbf{1 i}$ were synthesized in excellent yields from reaction of [1.1.1]propellane with commercially available ethyl iodopropanoate 6 (80\%), and iodoquinoline $7(85 \%),{ }^{[8]}$ using $\mathrm{Et}_{3} \mathrm{~B}$ initiation and photoredox catalysis $\left(\operatorname{Ir}(\mathrm{ppy})_{3} / \mathrm{blue}\right.$ LEDs), respectively. Kumada cross-coupling of iodo-BCP ester $1 \mathbf{k}$ with $\mathrm{PhMgBr}$, followed by hydrolysis, furnished $\mathrm{BCP}$-flurbiprofen 8 in $78 \%$ yield; coupling of 2-pyridyl iodoBCP 1i with 4-fluorophenylmagnesium bromide afforded brequinar analogue $9(66 \%) \cdot{ }^{[25]}$ Finally, access to aryl-BCPs featuring substituents not tolerated under Kumada coupling could be achieved by ipso-substitution ${ }^{[26]}$ of aryl silane $\mathbf{2} \mathbf{m}$ (Scheme 2b), for example with halides suitable for further elaboration by cross-coupling $(\mathbf{1 0}, \mathbf{1 1}),{ }^{[27]}$ or an electronwithdrawing acetyl group (12). ${ }^{[28]}$

In conclusion, we have developed a mild, efficient ironcatalyzed cross-coupling of iodo-BCPs and (hetero)aryl Grignard reagents, which represents the first such example of Kumada cross-coupling of tertiary iodides. The reaction is rapid, exhibits good functional group tolerance, and performs well on gram scale.

Applications to the functionalization of pharmaceutical derivatives, including the synthesis of two BCP drug analogues, demonstrate the potential of this transformation to access highly functionalized 1,3-C-disubstituted BCPs of direct relevance in medicinal chemistry settings.

\section{Acknowledgements}

J.N. thanks the Marie Skłodowska-Curie actions for an Individual Fellowship (GA No 786683). B.R.S., D.F.J.C. and H.D.P. thank the EPSRC Centre for Doctoral Training in
Synthesis for Biology and Medicine for studentships (EP/ L015838/1), generously supported by AstraZeneca, Diamond Light Source, Defence Science and Technology Laboratory, Evotec, GlaxoSmithKline, Janssen, Novartis, Pfizer, Syngenta, Takeda, UCB and Vertex. E.A.A. thanks the EPSRC for support (EP/S013172/1). F.N. thanks the Royal Society of Chemistry for an Undergraduate Research Bursary. We thank Dr Kirsten E. Christensen and Steven J. Mansfield for assistance with refinement of the X-ray crystal structures.

\section{Conflict of interest}

The authors declare no conflict of interest.

Keywords: bicyclopentane - bioisosteres - cross-coupling · homogeneous catalysis · iron

[1] a) Y. P. Auberson, C. Brocklehurst, M. Furegati, T. C. Fessard, G. Koch, A. Decker, L. La Vecchia, E. Briard, ChemMedChem 2017, 12, 590; b) A. F. Stepan, C. Subramanyam, I. V. Efremov, J. K. Dutra, T. J. O'Sullivan, K. J. DiRico, W. S. McDonald, A. Won, P. H. Dorff, C. E. Nolan, S. L. Becker, L. R. Pustilnik, D. R. Riddell, G. W. Kauffman, B. L. Kormos, L. Zhang, Y. Lu, S. H. Capetta, M. E. Green, K. Karki, E. Sibley, K. P. Atchison, A. J. Hallgren, C. E. Oborski, A. E. Robshaw, B. Sneed, C. J. O'Donnell, J. Med. Chem. 2012, 55, 3414; c) N. D. Measom, K. D. Down, D. J. Hirst, C. Jamieson, E. S. Manas, V. K. Patel, D. O. Somers, ACS Med. Chem. Lett. 2017, 8, 43; d) Y. L. Goh, Y. T. Cui, V. Pendharkar, V. A. Adsool, ACS Med. Chem. Lett. 2017, 8, 516; e) I. S. Makarov, C. E. Brocklehurst, K. Karaghiosoff, G. Koch, P. Knochel, Angew. Chem. Int. Ed. 2017, 56, 12774; f) G. A. Patani, E. J. LaVoie, Chem. Rev. 1996, 96, 3147.

[2] a) N. A. Meanwell, Chem. Res. Toxicol. 2016, 29, 564; b) For a review, see: P. K. Mykhailiuk, Org. Biomol. Chem. 2019, 17, 2839; c) G. M. Locke, S. S. R. Bernhard, M. O. Senge, Chem. Eur. J. 2019, 25, 4590; d) F. Lovering, J. Bikker, C. Humblet, J. Med. Chem. 2009, 52, 6752.

[3] a) For recent examples of the synthesis of bicyclo[1.1.1]pentanes, see: X. Zhang, R. T. Smith, C. Le, S. J. McCarver, B. T. Shireman, N. I. Carruthers, D. W. C. MacMillan, Nature 2020, 580, 220 ; b) J. H. Kim, A. Ruffoni, Y. S. S. Al-Faiyz, N. S. Sheikh, D. Leonori, Angew. Chem. Int. Ed. 2020, 59, 8225; Angew. Chem. 2020, 132, 8302; c) S. Yu, C. Jing, A. Noble, V. K. Aggarwal, Angew. Chem. Int. Ed. 2020, 59, 3917; d) R. M. Bär, P. J. Gross, M. Nieger, S. Bräse, Chem. Eur. J. 2020, 26, 4242; e) M. Kondo, J. Kanazawa, T. Ichikawa, T. Shimokawa, Y. Nagashima, K. Miyamoto, M. Uchiyama, Angew. Chem. Int. Ed. 2020, 59, 1970 ; f) for recent reviews of BCP synthesis and previous references, see: X. Ma, L. Nhat Pham, Asian J. Org. Chem. 2020, 9, 8; g) J. Kanazawa, M. Uchiyama, Synlett 2019, 30, 1.

[4] a) M. Messner, S. I. Kozhushkov, A. de Meijere, Eur. J. Org. Chem. 2000, 1137; b) N. Trongsiriwat, Y. Pu, Y. Nieves-Quinones, R. A. Shelp, M. C. Kozlowski, P. J. Walsh, Angew. Chem. Int. Ed. 2019, 58, 13416; c) for a rare example of room temperature anionic addition, see: R. A. Shelp, P. J. Walsh, Angew. Chem. Int. Ed. 2018, 57, 15857.

[5] J. D. D. Rehm, B. Ziemer, G. Szeimies, Eur. J. Org. Chem. 1999, 2079.

[6] J. Nugent, C. Arroniz, B. R. Shire, A. J. Sterling, H. D. Pickford, M. L. J. Wong, S. J. Mansfield, D. F. J. Caputo, B. Owen, J. J. Mousseau, F. Duarte, E. A. Anderson, ACS Catal. 2019, 9, 9568. 
[7] a) D. F. J. Caputo, C. Arroniz, A. B. Dürr, J. J. Mousseau, A. F. Stepan, S. J. Mansfield, E. A. Anderson, Chem. Sci. 2018, 9, 5295; b) M. L. J. Wong, J. J. Mousseau, S. J. Mansfield, E. A Anderson, Org. Lett. 2019, 21, 2408.

[8] See the Supporting Information for details.

[9] a) M. Nakamura, K. Matsuo, S. Ito, E. Nakamura, J. Am. Chem. Soc. 2004, 126, 3686; b) G. Cahiez, V. Habiak, C. Duplais, A. Moyeux, Angew. Chem. Int. Ed. 2007, 46, 4364; c) R. R. Chowdhury, A. K. Crane, C. Fowler, P. Kwong, C. M. Kozak, Chem. Commun. 2008, 94; d) T. Hatakeyama, Y.-i. Fujiwara, Y. Okada, T. Itoh, T. Hashimoto, S. Kawamura, K. Ogata, H Takaya, M. Nakamura, Chem. Lett. 2011, 40, 1030; e) X. Lin, F Zheng, F.-L. Qing, Organometallics 2012, 31, 1578; f) G. Bauer, C. W. Cheung, X. Hu, Synthesis 2015, 47, 1726; g) D. Parmar, L. Henkel, J. Dib, M. Rueping, Chem. Commun. 2015, 51, 2111; h) T. Hashimoto, T. Maruyama, T. Yamaguchi, Y. Matsubara, Y. Yamaguchi, Adv. Syn. Catal. 2019, 361, 4232; for recent reviews, see: i) T. L. Mako, J. A. Byers, Inorg. Chem. Front. 2016, 3, 766; j) A. Piontek, E. Bisz, M. Szostak, Angew. Chem. Int. Ed. 2018, 57, 11116; k) B. Barré, L. Gonnard, R. Campagne, S. Reymond, J. Marin, P. Ciapetti, M. Brellier, A. Guérinot, J. Cossy, Org. Lett. 2014, 16,6160

[10] To our knowledge, the only successful couplings of tertiary bromides and chlorides use adamantyl halides. See Ref. [9d], and S. K. Ghorai, M. Jin, T. Hatakeyama, M. Nakamura, Org. Lett. 2012, 14, 1066.

[11] To the best of our knowledge, only a single example of crosscoupling of an iodo-BCP has been described, which involves $\mathrm{Cu}-$ catalyzed Sonagashira coupling. See: A. Hazra, M. T. Lee, J. F. Chiu, G. Lalic, Angew. Chem. Int. Ed. 2018, 57, 5492.

[12] Entries 4-9 in Table 1 show the optimum results from the ligand screen; see the Supporting Information for full details. TMEDA and TMCD have been used as ligands in related Fe-catalzyed Kumada coupling; see Refs [9a,b] and [9k].

[13] a) R. B. Bedford, P. B. Brenner, E. Carter, P. M. Cogswell, M. F. Haddow, J. N. Harvey, D. M. Murphy, J. Nunn, C. H. Woodall, Angew. Chem. Int. Ed. 2014, 53, 1804; b) R. B. Bedford, D. W. Bruce, R. M. Frost, M. Hird, Chem. Commun. 2005, 4161; c) D. Noda, Y. Sunada, T. Hatakeyama, M. Nakamura, H. Nagashima, J. Am. Chem. Soc. 2009, 131, 6078.

[14] The concentration, equivalents, and rate of addition of the Grignard reagent also proved important factors in reaction optimization; for full details see the Supporting Information.

[15] a) S. L. Buchwald, C. Bolm, Angew. Chem. Int. Ed. 2009, 48, 5586; b) I. Thomé, A. Nijs, C. Bolm, Chem. Soc. Rev. 2012, 41, 979.

[16] See the Supporting Information for details of unsuccessful substrates.

[17] a) A. Hedström, Z. Izakian, I. Vreto, C.-J. Wallentin, P.-O. Norrby, Chem. Eur. J. 2015, 21, 5946; b) M. L. Neidig, S. H.
Carpenter, D. J. Curran, J. C. DeMuth, V. E. Fleischauer, T. E. Iannuzzi, P. G. N. Neate, J. D. Sears, N. J. Wolford, Acc. Chem. Res. 2019, 52, 140; c) R. B. Bedford, Acc. Chem. Res. 2015, 48, 1485.

[18] R. B. Bedford, M. Betham, D. W. Bruce, S. A. Davis, R. M. Frost, M. Hird, Chem. Commun. 2006, 1398.

[19] For further details and a discussion of mechanistic observations, see the Supporting Information.

[20] In contrast to the findings of the Nakamura and Caihez groups (Refs [9a,b]) no benefit was observed using superstoichiometric TMEDA (78\% yield was obtained using $160 \mathrm{~mol} \%$ TMEDA). Equally, in contrast to the findings of Bedford et al., (Ref.[13a]), reaction efficiency was severely compromised in the absence of TMEDA.

[21] R. B. Bedford, P. B. Brenner, D. Elorriaga, J. N. Harvey, J. Nunn, Dalton Trans. 2016, 45, 15811.

[22] a) G. Lefèvre, A. Jutand, Chem. Eur. J. 2014, 20, 4796; b) S. H. Carpenter, T. M. Baker, S. B. Muñoz, W. W. Brennessel, M. L. Neidig, Chem. Sci. 2018, 9, 7931.

[23] A. J. Sterling, A. Dürr, R. Smith, E. A. Anderson, F. Duarte, Chem. Sci. 2020, https://doi.org/10.1039/D0SC01386B.

[24] A. Hedström, U. Bollmann, J. Bravidor, P.-O. Norrby, Chem. Eur. J. 2011, 17, 11991.

[25] Low-temperature single-crystal X-ray diffraction data for $\mathbf{2} \mathbf{a}$ and 9 were collected with a (Rigaku) Oxford Diffraction SuperNova A diffractometer at $150 \mathrm{~K}$. All data were reduced using CrysAlisPro, solved using SuperFlip [L. Palatinus, G. Chapuis, J. Appl. Crystallogr. 2007, 40, 786-790] and the structures were refined using CRYSTALS. [P. W. Betteridge, J. R. Carruthers, R. I. Cooper, K. Prout, D. J. Watkin, J. Appl. Crystallogr. 2003, 36, 1487; R. I. Cooper, A. L. Thompson, D. J. Watkin, J. Appl. Crystallogr. 2010, 43, 1100-1107]; see the Supporting Information (CIF) for further details. CCDC 1991572, and 1991573 contain the supplementary crystallographic data for this paper. These data can be obtained free of charge from The Cambridge Crystallographic Data Centre.

[26] a) T. H. Chan, I. Fleming, Synthesis 1979, 761; b) C. Eaborn, J. Organomet. Chem. 1975, 100, 43.

[27] X.-H. Gu, R. Zong, N. S. Kula, R. J. Baldessarini, J. L. Neumeyer, Bioorg. Med. Chem. Lett. 2001, 11, 3049.

[28] a) C. D. Campbell, R. L. Greenaway, O. T. Holton, H. A. Chapman, E. A. Anderson, Chem. Commun. 2014, 50, 5187; b) G. Felix, M. Laguerre, J. Dunogues, R. Calas, J. Org. Chem. 1982, $47,1423$.

Manuscript received: March 19, 2020

Accepted manuscript online: April 28, 2020

Version of record online: 


\section{Communications}

Homogeneous Catalysis

J. Nugent, B. R. Shire, D. F. J. Caputo,

H. D. Pickford, F. Nightingale,

I. T. T. Houlsby, J. J. Mousseau,

E. A. Anderson* III-IIII

Synthesis of All-Carbon Disubstituted Bicyclo[1.1.1]pentanes by Iron-Catalyzed Kumada Cross-Coupling

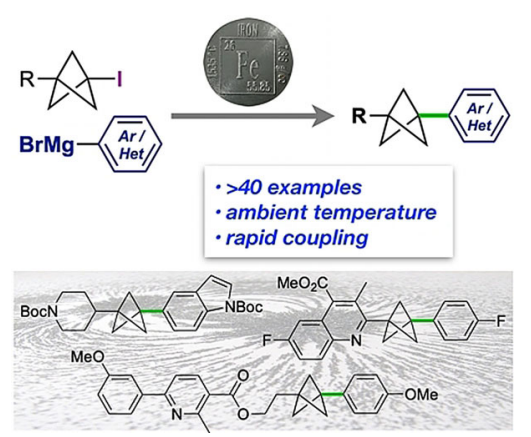

1,3-C-disubstituted bicyclo-

[1.1.1]pentanes (BCPs) are accessed from 1-iodo-BCPs by direct iron-catalyzed cross-coupling with aryl and heteroaryl Grignard reagents. This represents the first general use of iodo-BCPs as crosscoupling electrophiles, and the first Kumada coupling of tertiary iodides in general. Benefiting from short reaction times, mild conditions, and broad scope, it enables the synthesis of a wide range of BCPs including drug analogues. 